\title{
Clinical and histopathological manifestations of 17 cases of minor salivary glands sialolithiasis
}

\author{
You Fu ${ }^{1,2,3,4,5 \#}$, Dahe Zhang ${ }^{1,2,3,4,5 \#}$, Lizhen Wang ${ }^{2,3,4,5,6}$, Chaoji Shi ${ }^{1,2,3,4,5}$, Shengming Xu $\mathbf{u}^{1,2,3,4,5}$, \\ Shanghui Zhou ${ }^{1,2,3,4,5}$
}

${ }^{1}$ Department of Oral \& Maxillofacial - Head \& Neck Oncology, Shanghai Ninth People's Hospital, Shanghai Jiao Tong University School of Medicine, Shanghai, Shanghai, China; ${ }^{2}$ College of Stomatology, Shanghai Jiao Tong University, Shanghai, Shanghai, China; ${ }^{3}$ National Center for Stomatology, Shanghai, Shanghai, China; ${ }^{4}$ National Clinical Research Center for Oral Diseases, Shanghai, Shanghai, China; ${ }^{5}$ Shanghai Key Laboratory of Stomatology, Shanghai, Shanghai, China; ${ }^{\circ}$ Department of Oral Pathology, Shanghai Ninth People’s Hospital, Shanghai Jiao Tong University School of Medicine, Shanghai, Shanghai, China

Contributions: (I) Conception and design: S Zhou, Y Fu; (II) Administrative support: S Zhou; (III) Provision of study materials or patients: Y Fu, D Zhang, L Wang, S Xu, S Zhou; (IV) Collection and assembly of data: Y Fu, D Zhang; (V) Data analysis and interpretation: Y Fu, D Zhang; (VI) Manuscript writing: All authors; (VII) Final approval of manuscript: All authors.

"These authors contributed equally to this work and are co-first authors.

Correspondence to: Shanghui Zhou. Shanghai Ninth People’s Hospital, Shanghai Jiao Tong University School of Medicine, No. 639, Zhi-zao-ju Road, Shanghai 200011, China. Email: zhoushanghui@shsmu.edu.cn.

Background: Minor salivary gland sialolithiasis (MSGS) is rarely reported and can be easily misdiagnosed. This article was designed to provide updated clinical and pathological data, to contribute to the diagnosis and clinical treatment of MSGS.

Methods: The features of 17 cases of histopathologically diagnosed MSGS ranging from 2001 to 2019 were collected from the Shanghai Ninth People's Hospital Affiliated to the Medical College of Shanghai Jiao Tong University and were retrospectively analyzed.

Results: Male predisposition was found in these cases (female:male =5:12). The patients' ages ranged from 21 to 83 years, with a mean age of $61.1( \pm 14.8)$ years. Most cases were identified within $50-70$ years old $(\mathrm{n}=12 ; 70.6 \%)$, while 4 patients $(23.5 \%)$ were aged $\geq 70$ years. The most common anatomical location of the sialoliths was cheek $(n=8 ; 47.0 \%)$, followed by the upper lip $(n=7 ; 41.2 \%)$ and the lower lip $(n=7 ; 41.2 \%)$. Only 3 cases $(17.6 \%)$ were initially diagnosed correctly as MSGS. The lesions included gland inflammation $(\mathrm{n}=15 ; 88.2 \%)$, ductal ectasia $(\mathrm{n}=12 ; 70.6 \%)$ and ductal epithelium hyperplasia $(\mathrm{n}=8 ; 47 \%)$, while parenchyma or mucosa inflammations were also seen in 6 cases $(35.3 \%)$.

Conclusions: Our study showed an age tendency and a male predilection of MSGS. We reasonably believed that MSGS was an underestimated disease and should be distinguished prudently from other diseases.

Keywords: Sialolithiasis; minor salivary glands; histopathology

Received: 13 December 2020; Accepted: 09 May 2021; Published: 10 June 2021.

doi: $10.21037 /$ fomm-20-87

View this article at: http://dx.doi.org/10.21037/fomm-20-87

\section{Introduction}

Minor salivary glands sialolithiasis (MSGS) is a kind of sialolithiasis occurred in minor salivary glands but rarely reported (1-3). The first article on the subject could date back to 1865 by Papin (4). The common clinical manifestation of MSGS is a nodular, hard or tender lump with good mobility. Although having a long history, MSGS is usually misdiagnosed due to its undistinguishable clinical and imaging manifestations. Sialadenitis, mucocele, fibroma, pleomorphic adenoma (PA) 
and hemangioma is the most common wrong diagnoses for MSGS patients $(5,6)$.

The etiology of MSGS is still unclear. Recent study found that sialoliths formation could be divided into two phases: crystallization phase and growing phase. During the crystallization stage, disequilibrium of electrolyte leads to changes of solubility of calcium and phosphorus, calcium deposit gradually, combining with mucopolysaccharide to form calcified core. In the growing stage, inorganic and organic components deposit layer by layer and sialolith form gradually. In the crystallization stage, calciumpermeated phosphorite and calcium oxalate are located in the calcification front and can be further converted into apatite crystal structure, which is more stable (7).

There are 450 to 750 minor salivary glands distributed in head and neck region, most of which are located in the lips, cheeks, tongue, floor of the mouth, hard palate, soft palate, uvula, posterior area of molars, and surrounding tonsils. Among these regions, the cheek and lip are the most common area to be reported as occurring a MSGS (5). Histologically, the sialoliths tended to be submucosal and constituted by multiple layers with diverse degrees of mineralization. Moreover, chronic parenchymal or mucosa inflammation could be commonly seen in MSGS as well as squamous metaplasia and duct ectasia.

MSGS may be a kind of underestimated disease for its clinical features which were similar to other oral nodules (6). Therefore, we collected 17 cases of MSGS and identified the clinicopathological characterizations of these cases, in order to analyze the specifics of the disease to contribute to the diagnosis and clinical treatment.

\section{Methods}

\section{Tissue specimens}

Histopathology diagnoses ranging from 2001 to 2019 were obtained from the Shanghai Ninth People's Hospital Affiliated to the Medical College of Shanghai Jiao Tong University. All diagnoses containing the key words "minor salivary gland" and "sialolithiasis" were collected. MSGS diagnosis was verified only when sialoliths existed in the minor salivary gland. Individual data such as age, gender, anesthesia method and therapeutic regimen were collected for analysis. All the excised specimens were fixed in 10\% formalin and embedded in paraffin. The formalin fixed paraffin-embedded (FFPE) tissues were cut into 5- $\mathrm{mm}$ slices. Hematoxylin-eosin (HE) staining was performed and an inverted microscope was used to observe. The study was conducted in accordance with the Declaration of Helsinki (as revised in 2013). This retrospective study was approved by the Institutional Review Boards of Shanghai Jiao Tong University School of Medicine (SH9H-2021-T105-2) and individual consent for this retrospective analysis was waived.

\section{Statistical analysis}

The results were analyzed with SPSS 25.0 and were expressed as the percentage.

\section{Results}

Within the 19-year period, 17 cases of MSGS were identified. The features of these cases are presented in Table 1, including gender, age, anatomical location of the sialoliths, the biopsy consequences of the duct, ductal epithelium, gland and parenchyma or mucosa, and treatment.

In detail, the patients' ages ranged from 21 to 83 years, with a mean age of $61.1( \pm 14.8)$ years. Most cases were identified within $50-70$ years $(n=12 ; 70.6 \%)$, while four patients $(23.5 \%)$ were aged $\geq 70$ years. In gender, male predisposition was found in these cases (female:male $=5: 12)$. The most common anatomical location of the sialoliths was the cheek $(n=8 ; 47.0 \%)$, followed by the upper lip $(n=7 ; 41.2 \%)$ and the lower lip $(n=7 ; 41.2 \%)$. Among the 17 cases, only 3 cases (17.6\%) were initially diagnosed correctly as MSGS and the initial presumptive diagnoses included sialadenitis, mucocele, fibroma, PA and hemangioma. The diagnoses were made by visual assessment or X-ray. Clinicians tended to omit MSGS as a diagnosis option. All the patients had undergone an excision under general anesthesia and were recovery after surgery. Histopathological analysis showed that $23.5 \%$ $(n=4)$ of MSGS were multiple. The lesions included gland inflammation $(n=15 ; 88.2 \%)$, ductal ectasia $(n=12 ; 70.6 \%)$ and ductal epithelium hyperplasia $(n=8 ; 47 \%)$, while parenchyma or mucosa inflammations were also seen in 6 cases $(35.3 \%)$.

Representative clinical and histopathological images of MSGS were shown in Figures 1 and 2. The HE staining showed homogeneous or heterogeneous characterizations.

\section{Discussion}

It was reported that MSGS is most common in the upper lip (49.2\%) and cheek (37.3\%), followed by the lower lip 
Table 1 Clinical and histological summary of the 17 MSGS in our study

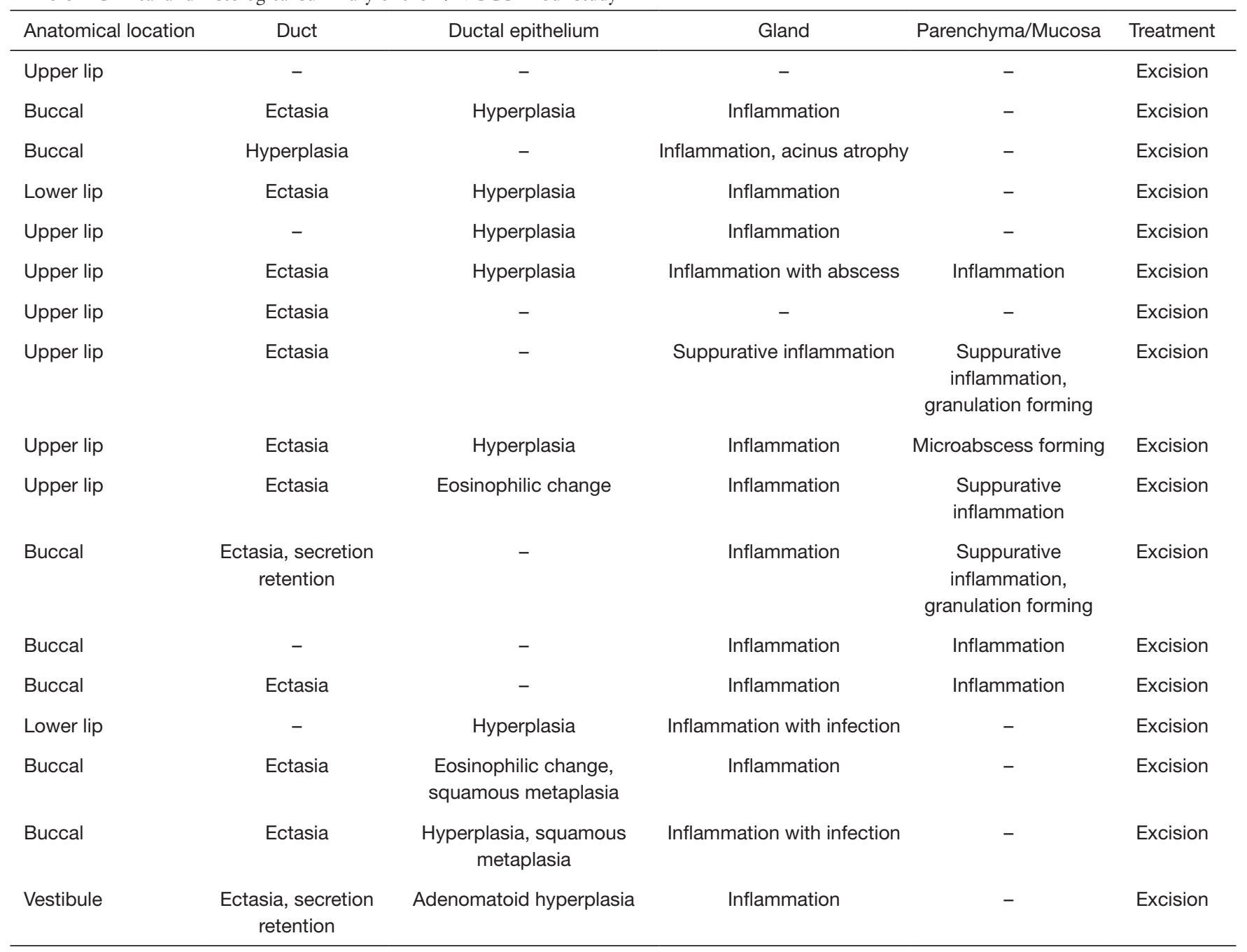

MSGS, minor salivary gland sialolithiasis.

(5.5\%), vestibule $(4.7 \%)$, and palate and tongue $(1.6 \%)$ $(5,8)$. Due to the rarely diagnosed rate and the small number of cases, we reasonably believed that MSGS was an underestimated disease in the clinical work. In our study, we identified that the most occurrence age was $50-70$ years old, including the middle-aged and the elder, which accorded with the previous studies $(3,5)$.

The etiology of MSGS is still unclear because of the complex formation of sialolithiasis. At the beginning of the formation, a nucleus of sialolith is formed, consisting of exfoliated epithelial cell products, bacteria, foreign matter and bacterial decomposition products which is covered with deposited calcium $(9,10)$. Then, the formation process could be divided into two phases: crystallization phase and growing phase as we mentioned in the introduction. Besides, Kasaboğlu et al. identified the ratio of calcium and phosphorus $(1.50-2.36)$ in sialoliths by using $\mathrm{X}$-ray energy spectrometer (11). The main crystal formation in sialoliths is hydroxyapatite $\left[\mathrm{Ca}_{5}\left(\mathrm{PO}_{4}\right)_{3} \mathrm{OH}\right](12)$, followed by tricalcium phosphate $\left[\mathrm{Ca}_{3}\left(\mathrm{PO}_{4}\right)_{2}\right]$ and some other crystals with less content, such as calcium-permeated phosphostone $\left(\mathrm{CaHPO}_{4} \cdot 2 \mathrm{H} 2 \mathrm{O}\right)$ and calcium oxalate $\left(\mathrm{CaC}_{2} \mathrm{O}_{4} \cdot 2 \mathrm{H}_{2} \mathrm{O}\right)(13)$. Therefore, existence of substances as a core, property alteration of saliva and calcium deposition account for the most important conditions of sialolithiasis formation.

The main histopathological features of MSGS are similar to chronic obstructive sialadenitis, including duct ectasia, acinus atrophy and secretions retention (14). MSGS could 

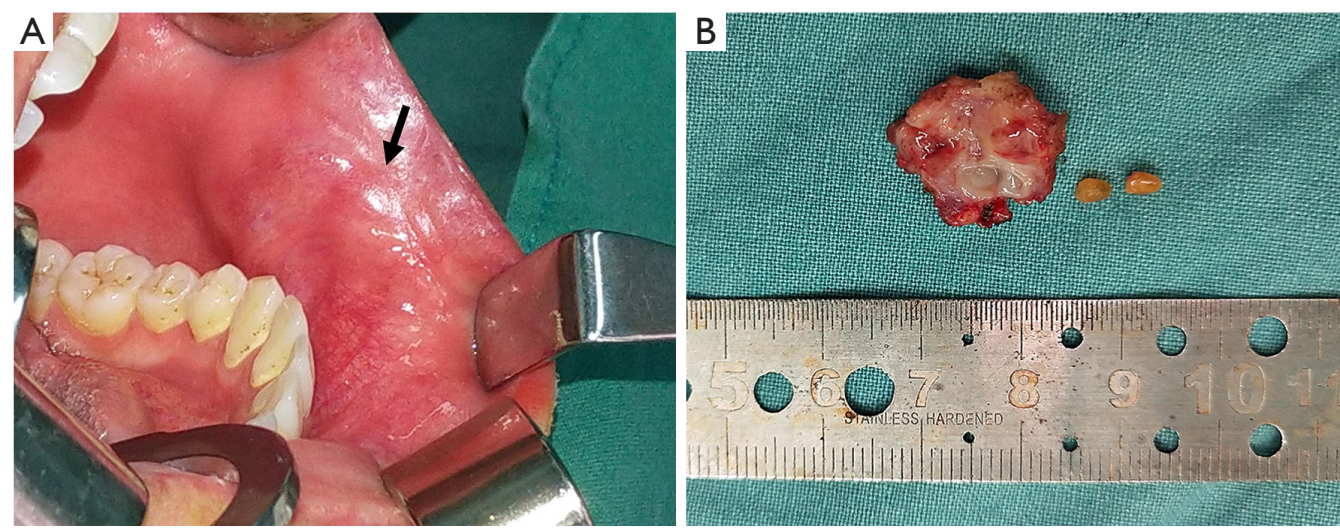

Figure 1 Clinical view of a 70-year-old man who had a buccal swelling and pain. (A) An excision was performed (the black arrow is the lesion); (B) two sialoliths were found in the mass.
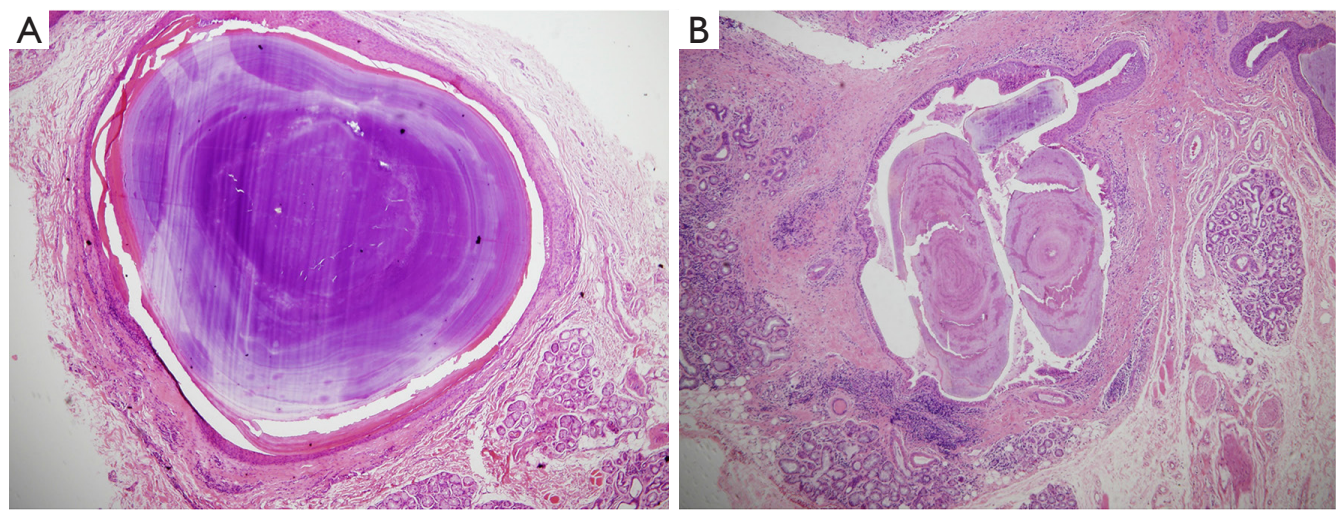

Figure 2 Representative image of HE staining of two cases (magnification is 40x). (A) Single sialolith was found with a little inflammation and ductal ectasia; (B) multiple sialoliths were found with apparent inflammation, ductal ectasia and ductal epithelium hyperplasia.

be characterized pathologically as mostly highly-mineralized laminated calculi, single or multiple, accompanied with duct ectasia, ductal epithelium hyperplasia and squamous metaplasia, gland inflammation and parenchyma or mucosa inflammation (15). Moreover, MSGS could cause secretion retention of glands, further resulting in inflammation, and gland infection is also found in many cases (16).

MSGS is a kind of chronic disease, whose common clinical manifestation is a nodular, hard or tender lump with good mobility. However, due to its similarity of clinical characteristics with other disease, it was reported that less than $20 \%$ sialolithiasis were initially diagnosed correctly (15). Moreover, sialoliths may move on their own, thus increasing the difficulty of precise diagnosis. MSGS can be easily diagnosed by biopsy, but before surgery, it is still of vital importance to make an accurate diagnosis.
Therefore, we'd like to discuss the differential diagnosis between MSGS and other diseases in this article.

If the auxiliary examinations, especially X-ray, ultrasound image, can check out the calculus, a firm diagnosis can be reached. However, a part of sialoliths might be radiotransparent and do not show characteristic appearance of calculus in the imaging examinations, due to its tiny volume $(15,17)$. If this happened, MSGS should be distinguished from mucocele, fibroma, malignant or benign tumors of accessory parotid gland, submucosal foreign substances and sialadenitis. For example, mucocele is a common exophytic lesion in the minor salivary glands, which has a bluish to translucent color, soft touch and dome-shape, varying from 0.3 to $2.2 \mathrm{~cm}(18,19)$. Therefore, the visual examination and palpation are essential and the non-enhanced computed tomography (CT) may be 
conducive to a correct diagnosis. Besides, fibroma is a traumatic lesion with a nodular appearance. High resultrasound image may be a good way to distinguish fibroma and MSGS (20). Furthermore, when MSGS has an adhesion to the surrounding tissue due to the inflammation, clinicians perhaps cannot tell the difference between MSGS and malignant tumors. The symptoms of malignant tumors are conspicuous, such as the irregular surface and the indistinct border of the tumor, pain, cervical lymphadenectasis, facioplegia, open mouth difficulty and cachexia (21), which MSGS will never lead up to. In benign tumors, CT and magnetic resonance imaging (MRI) can be applied. For example, on dynamic contrast-enhanced CT and MR imaging, most PA show continuously and gradually increased enhancement (22).

Nowadays, the clinical application of salivary gland endoscope has greatly improved the detection rate and diagnostic accuracy of sialoliths. More and more X-ray negative calculi and multiple calculi can be clearly diagnosed by using endoscope (23-25). However, some of sialolithiasis even does not have obvious symptoms which adds difficulty to the early diagnosis, which reminds us to pay more attention to this disease. It would be terrible if a MSGS with serious inflammation was misdiagnosed as a malignant tumor, for an extended excision or even an elective neck dissection might be taken as a treatment. Above all, the medical history, visual examination, palpation and auxiliary examinations for the diagnosis of MSGS need to be taken seriously by clinicians.

Admittedly, the limitation of the study is that few clinicians made a imaging test before treatment. So the information of the patients' imaging test was little.

With respect to the therapeutic regimen of MSGS, excision under local or general anesthesia was widely believed to be the first choice. Sialoliths and gland involved should be removed entirely in the operation. Once excised, MSGS has a favorable prognosis. Local and distant recurrences were not observed in all 17 cases.

\section{Conclusions}

To summarize, most patients with MSGS were found aged over 50 years old, and were predominantly male. The common sites of the disease were buccal mucosa and upper lip. Clinicians should pay more attention to this disease, especially unknown nodules in upper lips and buccal mucosa. Our study identified some specific characterizations of MSGS and distinguished MSGS from other diseases in the hope that MSGS could be diagnosed more correctly to provide precise treatment for patients.

\section{Acknowledgments}

The authors acknowledge The Ninth People's Hospital Affiliated to the Shanghai Jiao Tong University School of Medicine for financial support of the National Key Research and Development Program of China (2017YFC0908500) and the grant of Shanghai Pujiang Program (No. 18PJD026). This research did not receive any specific grant from funding agencies in the public, commercial, or notfor-profit sectors.

Funding: This work was supported by the grant of Shanghai Pujiang Program (No. 18PJD026) and the National Natural Science Foundation of China (No. 81802697).

\section{Footnote}

Data Sharing Statement: Available at https://fomm. amegroups.com/article/view/10.21037/fomm-20-87/dss

Peer Review File: Available at https://fomm.amegroups.com/ article/view/10.21037/fomm-20-87/prf

Conflicts of Interest: All authors have completed the ICMJE uniform disclosure form (available at https://fomm. amegroups.com/article/view/10.21037/fomm-20-87/coif). The authors have no conflicts of interest to declare.

Ethical Statement: The authors are accountable for all aspects of the work in ensuring that questions related to the accuracy or integrity of any part of the work are appropriately investigated and resolved. The study was conducted in accordance with the Declaration of Helsinki (as revised in 2013). This retrospective study was approved by the Institutional Review Boards of Shanghai Ninth People's Hospital, Shanghai Jiao Tong University School of Medicine (SH9H-2021-T105-2) and individual consent for this retrospective analysis was waived.

Open Access Statement: This is an Open Access article distributed in accordance with the Creative Commons Attribution-NonCommercial-NoDerivs 4.0 International License (CC BY-NC-ND 4.0), which permits the noncommercial replication and distribution of the article with the strict proviso that no changes or edits are made and the original work is properly cited (including links to both the 
formal publication through the relevant DOI and the license). See: https://creativecommons.org/licenses/by-nc-nd/4.0/.

\section{References}

1. Abe A, Kurita K, Hayashi H, et al. A case of minor salivary gland sialolithiasis of the upper lip. Oral Maxillofac Surg 2019;23:91-4.

2. Kessler AT, Bhatt AA. Review of the Major and Minor Salivary Glands, Part 1: Anatomy, Infectious, and Inflammatory Processes. J Clin Imaging Sci 2018;8:47.

3. Wang WC, Chen CY, Hsu HJ, et al. Sialolithiasis of minor salivary glands: A review of 17 cases. J Dent Sci 2016;11:152-5.

4. Papin D. Salivary calculus. Dent Cosmos 1864-1865;6:136.

5. Ben Lagha N, Alantar A, Samson J, et al. Lithiasis of minor salivary glands: current data. Oral Surg Oral Med Oral Pathol Oral Radiol Endod 2005;100:345-8.

6. Brazao-Silva MT, Prosdocimi FC, Lemos-Junior CA, et al. Clinicopathological aspects of 25 cases of sialolithiasis of minor salivary glands. Gen Dent 2015;63:e22-6.

7. Tanaka N, Ichinose S, Adachi Y, et al. Ultrastructural analysis of salivary calculus in combination with $\mathrm{X}$-ray microanalysis. Med Electron Microsc 2003;36:120-6.

8. Favia G, Capodiferro S, Turco M, et al. Lithiasis of minor salivary glands of the upper lip. Clinico-pathological report of a case with unusual presentation. Minerva Stomatol 2004;53:179-83.

9. Lee LT, Wong YK. Pathogenesis and diverse histologic findings of sialolithiasis in minor salivary glands. J Oral Maxillofac Surg 2010;68:465-70.

10. Alcure ML, Della Coletta R, Graner E, et al. Sialolithiasis of minor salivary glands: a clinical and histopathological study. Gen Dent 2005;53:278-81.

11. Kasaboğlu O, Er N, Tümer C, et al. Micromorphology of sialoliths in submandibular salivary gland: a scanning electron microscope and X-ray diffraction analysis. J Oral Maxillofac Surg 2004;62:1253-8.

12. Grases F, Santiago C, Simonet BM, et al. Sialolithiasis:

doi: 10.21037/fomm-20-87

Cite this article as: Fu Y, Zhang D, Wang L, Shi C, $\mathrm{Xu} \mathrm{S}$, Zhou S. Clinical and histopathological manifestations of 17 cases of minor salivary glands sialolithiasis. Front Oral Maxillofac Med 2021;3:12. mechanism of calculi formation and etiologic factors. Clin Chim Acta 2003;334:131-6.

13. Riesco JM, Juanes JA, Díaz-González MP, et al. Crystalloid architecture of a sialolith in a minor salivary gland. J Oral Pathol Med 1999;28:451-5.

14. Bajpai M, Pardhe N. Sialolithiasis Of Lower Lip Histopathological Interpretation. J Ayub Med Coll Abbottabad 2017;29:529.

15. Anneroth G, Hansen LS. Minor salivary gland calculi. A clinical and histopathological study of 49 cases. Int J Oral Surg 1983;12:80-9.

16. Ho V, Currie WJ, Walker A. Sialolithiasis of minor salivary glands. Br J Oral Maxillofac Surg 1992;30:273-5.

17. Crawford WH Jr, Guernsey LH. Sialolithiasis of minor salivary glands: report of case. J Oral Surg 1969;27:649-52.

18. Liu JL, Zhang AQ, Jiang LC, et al. The efficacy of polidocanol sclerotherapy in mucocele of the minor salivary gland. J Oral Pathol Med 2018;47:895-9.

19. Choi YJ, Byun JS, Choi JK, et al. Identification of predictive variables for the recurrence of oral mucocele. Med Oral Patol Oral Cir Bucal 2019;24:e231-e235.

20. Di Stasio D, Lauritano D, Paparella R, et al. Ultrasound imaging of oral fibroma: a case report. J Biol Regul Homeost Agents 2017;31:23-6.

21. Bagan J, Sarrion G, Jimenez Y. Oral cancer: clinical features. Oral Oncol 2010;46:414-7.

22. Kato H, Kawaguchi M, Ando T, et al. Pleomorphic adenoma of salivary glands: common and uncommon CT and MR imaging features. Jpn J Radiol 2018;36:463-71.

23. Bowen MA, Tauzin M, Kluka EA, et al. Diagnostic and interventional sialendoscopy: a preliminary experience. Laryngoscope 2011;121:299-303.

24. Singh PP, Gupta N, Goyal A, et al. Interventional sialendoscopy for parotid ductal calculi: our preliminary experience. Indian J Otolaryngol Head Neck Surg 2012;64:252-6.

25. Walvekar RR, Razfar A, Carrau RL, et al. Sialendoscopy and associated complications: a preliminary experience. Laryngoscope 2008;118:776-9. 